\title{
Study on treatment method of low efficiency well in S12 block
}

\author{
Zhang Changyan ${ }^{1, *}$ \\ ${ }^{1}$ Research Institute of exploration and Development of Daqing Oilfield Co. Ltd, Ranghulu District, Daqing City, Heilongjiang Province, \\ China
}

\begin{abstract}
In recent years, the production decline of some oilfields is obvious, and a large number of oil wells begin to be in inefficient or ineffective production. Only by controlling these wells can the oilfields maintain effective production. By means of dynamic and static multidisciplinary integrated research, through elaborate dissection of typical potential blocks, the optimal treatment measures are selected from four aspects of " reservoir heterogeneity and production status, type and distribution law of remaining oil, causes of low efficiency wells, classification and comprehensive treatment countermeasures and methods", so as to provide technical support for potential tapping and comprehensive treatment of old oilfields.
\end{abstract}

\section{Introduction}

With the extension of development time, the production decline of some oilfields is obvious, and a large number of oil wells begin to be in inefficient or ineffective production. Only by controlling these wells can the oilfields maintain effective production ${ }^{[1]}$. Block S12 is a rectangular fault block cut by faults, and its long side is NW trending. The top surface of the reservoir in this block is a near slope structure with high in the North and low in the South and high in the East and low in the West. The overall structural trend of the block is obvious. Due to the cutting effect of faults, the block forms a relatively independent oil-water system, and a favorable oil-gas enrichment area is formed locally. There are 77 production wells and 45 water injection wells in this block, with an average daily oil production of $1.81 \mathrm{t}$ and water cut of $76.67 \%$. There are 26 oil wells put into production before 2000, including 20 low efficiency wells with daily oil production less than 1t, including 11 shut in wells. And there are 51 infill wells in the block, including 31 low efficiency wells with daily oil production less than $1 \mathrm{t}$, including 10 long shut in wells.

\section{Analysis of production status and remaining oil}

\subsection{Analysis of oil production statu}

Through the quantitative analysis of sedimentary units in each block, starting from the drilling conditions of sandstone and effective thickness. It is found that there are great differences in drilling conditions in different well areas and different horizons. Generally, the oil reservoir is mainly controlled by lithology, and there is a good matching relationship between sandstone development zone and oil reservoir development zone on the plane. The sand bodies in the north part are relatively developed and vary greatly in the vertical direction, while the sand bodies in the south part are relatively small in development scale and evenly distributed in the vertical direction.

The sand bodies in the north part are relatively developed, mainly two-way connectivity, with the twoway connectivity ratio of $52.26 \%$ and the one-way connectivity ratio of $31.68 \%$. Layer $\mathrm{A} 3$, which is the main layer in this part, is a large river channel. The sand bodies in the south part are scattered, with narrow channels, mainly one-way connectivity, with the oneway connectivity ratio of $48 \%$ and two-way connectivity ratio of $29.09 \%$, and non connectivity ratio of $16.36 \%$. These problems are found through the study of the connectivity between the south and the north part of the block.

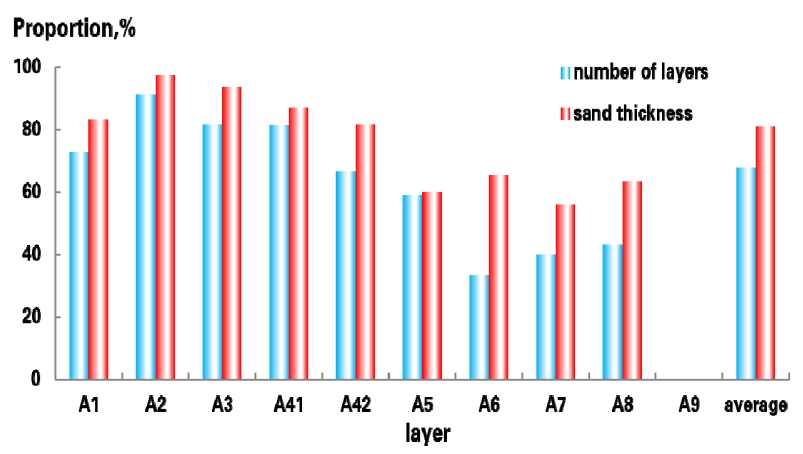

Fig. 1. Histogram of water absorption of each layer in S12 block.

It is found that the large distributary channel and the small distributary channel can be utilized well. The results show that the large distributary channel has the best production effect, the thickness ratio of water absorbing sandstone reaches $91.0 \%$, followed by the small distributary channel, the thickness ratio of water

* Corresponding author: zhangchangyan@petrochina.com.cn 
absorbing sandstone is $81.5 \%$, and the main sheet sand and non main sheet sand are poorly produced. The statistical results of liquid production profile show that the large distributary channel and small distributary channel can be effectively utilized, and the effective thickness ratio of liquid production is $100 \%$ and $84.9 \%$, while the liquid production ratio of main sheet sand is

Table 1. Production degree of different permeability and thickness of reservoir in S12 block.

\begin{tabular}{|c|c|c|c|c|c|}
\hline \multirow{2}{*}{$\begin{array}{c}\text { Thickness } \\
\text { classification /m }\end{array}$} & \multicolumn{2}{|c|}{ Production rate $/ \%$} & \multirow{2}{*}{$\begin{array}{c}\text { Permeability } \\
\text { classification } \\
110^{-3} \mu \mathrm{m}^{2} \\
\end{array}$} & \multicolumn{2}{|c|}{ Production rate $/ \%$} \\
\hline & Number of layers & Thickness & & Number of layers & Thickness \\
\hline$<1 \mathrm{~m}$ & 39.3 & 42.8 & $<50$ & 56.1 & 68.7 \\
\hline $1-2 m$ & 67.4 & 71.5 & $50-100$ & 67.3 & 79.9 \\
\hline $2-3 m$ & 83.3 & 84.1 & $>=100$ & 88.0 & 92.5 \\
\hline$>=3 \mathrm{~m}$ & 90.0 & 92.2 & & & \\
\hline Total & 67.8 & 81.1 & Total & 67.8 & 81.1 \\
\hline
\end{tabular}

The statistical results show that the greater the thickness of the oil layer, the higher the production ratio, and the production degree of medium and high permeability reservoir is high, and the production proportion of low permeability reservoir is small (Table 1).

\subsection{Study on the type and distribution of remaining oil}

Three dimensional geological modeling and reservoir numerical simulation were carried out in the study area, and the distribution of remaining oil between wells and layers in the basic well pattern was analyzed by using the inspection well data. The results show that the water washing parts of the oil layer between wells are mainly concentrated in the lower part of the positive rhythm oil layer, the upper part of the main layer and the non main layer are basically not washed, and the remaining oil is relatively rich.

By analyzing the types of remaining oil and its distribution law, it is found that there is a great difference in the distribution of the remaining oil in the vertical direction. The remaining oil mainly exists in the main layer with good production condition and high water cut. Layer A2 and A3 have a high degree of recovery, and the thickness ratio of the remaining oil is $31.9 \%$ and $34.2 \%$. The remaining oil is also mainly undeveloped in the layer. The remaining oil thickness of main layers is relatively large. Layer A3, A41, A2 and A5, the remaining oil thickness of whom accounting for only $25.5 \%$. Undeveloped reserves mainly exist in sheet sand and small distributary channel. According to the statistics of production status of different vertical oil layers, it is found that the overall production proportion of main oil layers is higher than that of non main oil layers (Fig. 1).

$29.1 \%, 11.9 \%, 11.2 \%$ and $9.1 \%$, is still the key object of subsequent adjustment and tapping potential. The non main reservoir is poor in production, small in scale, and the adjustment potential is small (Fig. 2).

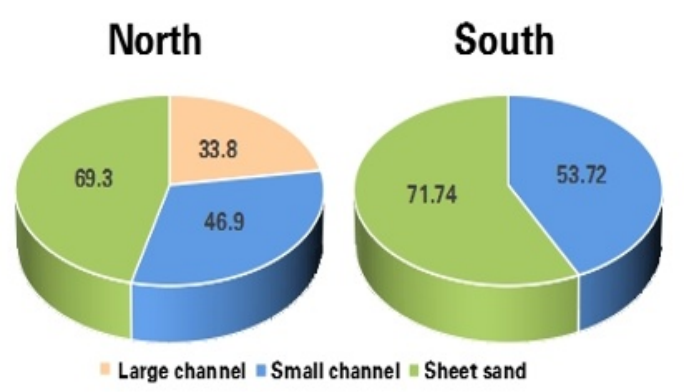

Fig. 2. Remaining oil ratio of different sandbody reservoirs.

The remaining oil distribution in the north and south parts of the block is quite different, and the ratio of producing thickness in the north part is about $60 \%$. Among them, the large distributary channel reservoir is well developed with high degree of water washing, and the ratio of producing thickness reaches $66.2 \%$. The potential of the north part is mainly unperforated, plane interference and poor water absorption of water injection wells. The channel of the south part is narrow and small, and the reservoir is mainly affected by one-way effect, and the ratio of producing thickness is low, which is $43.5 \%$. The main reasons for the formation of remaining oil are heterogeneity in the formation, unperforation and imperfect injection production (Table 2).

Table 2. Remaining oil status of different sandbody reservoirs in $\mathrm{S} 12$ block.

\begin{tabular}{|c|c|c|c|c|c|c|}
\hline \multirow[b]{2}{*}{ Block } & \multirow[b]{2}{*}{$\begin{array}{c}\text { Types of } \\
\text { sandbodies }\end{array}$} & \multicolumn{5}{|c|}{ Remaining oil type and thickness percentage $/ \%$} \\
\hline & & $\begin{array}{c}\text { Intraformational } \\
\text { heterogeneity }\end{array}$ & Unperforated & $\begin{array}{l}\text { Imperfect } \\
\text { injection } \\
\text { production }\end{array}$ & $\begin{array}{c}\text { Plane } \\
\text { interference }\end{array}$ & $\begin{array}{l}\text { Poor water } \\
\text { absorption }\end{array}$ \\
\hline \multirow{4}{*}{$\begin{array}{l}\text { North } \\
\text { part }\end{array}$} & Large channel & 82.57 & 8.47 & & & 8.96 \\
\hline & Small channel & 29.3 & 26.27 & 21.5 & 9.39 & 13.54 \\
\hline & Sheet sand & & 4.43 & 27.21 & 60.13 & 8.23 \\
\hline & Subtotal & 43.79 & 17.26 & 14.85 & 12.84 & 11.26 \\
\hline
\end{tabular}




\begin{tabular}{|c|c|c|c|c|c|c|}
\multirow{4}{*}{$\begin{array}{c}\text { South } \\
\text { part }\end{array}$} & Small channel & 25.87 & 54.28 & 16.94 & & 2.91 \\
\cline { 2 - 7 } & Sheet sand & & 49.24 & 15.15 & 28.79 & 6.82 \\
\cline { 2 - 7 } & Subtotal & 20.85 & 53.31 & 16.59 & 5.58 & 3.67 \\
\hline \multicolumn{2}{|c|}{ Total } & 35.48 & 30.32 & 15.48 & 10.21 & 8.51 \\
\hline
\end{tabular}

On the plane, the remaining reserves of layer $\mathrm{A} 3, \mathrm{~A} 2$, A41 and A5 in S12 block account for 74\%, which is the main target of tapping potential. The remaining oil in layer A3 belongs to large area distribution type, and the remaining oil in layer A2, A41 and A5 belongs to local distribution type, the remaining reserves of layer A42, A6, A1, A7, A8 and A9, which are the non-essential layers account for $26 \%$, with small adjustment potential and scattered distribution type.

\section{Cause analysis of low efficiency well}

There are 51 low efficiency wells (32 wells in north part and 19 wells in south part) in S12 block, accounting for $66.3 \%$ (Table 3).

Table 3. Production situation of low efficiency wells in S12 block.

\begin{tabular}{|c|c|c|c|c|c|c|c|}
\hline \multirow[b]{2}{*}{ Block } & \multirow[b]{2}{*}{$\begin{array}{l}\text { Causes of } \\
\text { inefficiency }\end{array}$} & \multirow[b]{2}{*}{$\begin{array}{c}\text { Number } \\
\text { of wells / } \\
\text { well }\end{array}$} & \multirow[b]{2}{*}{$\begin{array}{c}\text { Number of } \\
\text { treatment } \\
\text { wells / well }\end{array}$} & \multicolumn{3}{|c|}{ Production situation } & \multirow{2}{*}{$\begin{array}{c}\text { Cumulative oil } \\
\text { production of } \\
\text { single well } \\
/ 10^{4} t\end{array}$} \\
\hline & & & & $\begin{array}{c}\text { Fluid } \\
\text { production } \\
/ / \mathbf{t}\end{array}$ & $\begin{array}{c}\text { Oil } \\
\text { production } \\
/ / t\end{array}$ & $\begin{array}{c}\text { water cut } \\
\quad / \%\end{array}$ & \\
\hline \multirow{4}{*}{$\begin{array}{l}\text { North } \\
\text { part }\end{array}$} & High recovery & 7 & 4 & 3.5 & 0.1 & 96.5 & 2.2909 \\
\hline & $\begin{array}{c}\text { Intraformational } \\
\text { heterogeneity }\end{array}$ & 10 & 5 & 5.9 & 0.6 & 90.7 & 0.3746 \\
\hline & $\begin{array}{l}\text { Interlaminar } \\
\text { interference }\end{array}$ & 14 & 6 & 5.1 & 0.2 & 9.3 & 0.3027 \\
\hline & Thin and poor layer & 1 & 1 & 1.5 & 0 & 98.7 & 0.0105 \\
\hline \multirow{7}{*}{$\begin{array}{l}\text { South } \\
\text { part }\end{array}$} & High recovery & 5 & 3 & 2.5 & 0.4 & 83.2 & 2.0274 \\
\hline & $\begin{array}{c}\text { Intraformational } \\
\text { heterogeneity }\end{array}$ & 3 & 2 & 2 & 0.3 & 83 & 0.6122 \\
\hline & $\begin{array}{l}\text { Interlaminar } \\
\text { interference }\end{array}$ & 3 & 1 & 4 & 0 & 100 & 0.2656 \\
\hline & Thin and poor layer & 5 & 5 & 1.8 & 0.3 & 83.3 & 0.0112 \\
\hline & $\begin{array}{l}\text { Imperfect injection } \\
\text { production }\end{array}$ & 1 & 1 & 2.4 & 0 & 100 & 0.0075 \\
\hline & Oil-water layer & 1 & 1 & 6.5 & 0 & 100 & 0.0053 \\
\hline & $\begin{array}{l}\text { Ineffective water } \\
\text { injection }\end{array}$ & 1 & 1 & 1.2 & 0.8 & 31.4 & 0.0336 \\
\hline
\end{tabular}

The low efficiency wells in north part of the block can be divided into four kinds: high recovery, interlaminar interference, intraformational heterogeneity, thin and poor layer. Layer A3, the main oil layer of the north part, has a high utilization degree, which makes other layers difficult to produce, this phenomenon causes interlaminar interference being the main reason for low efficiency of oil wells. Meanwhile, the recovery degree of old wells is high, while the infill wells have high water cut due to water flooding in the main oil layer, which is also an important reason for the formation of low efficiency wells.

The low efficiency wells in south part can be divided into 7 kinds: high recovery, interlaminar interference, intraformational heterogeneity, thin and poor layer, oilwater layer, imperfect injection and production, and ineffective water injection(Fig. 3).

The statistical analysis of old wells and infill wells shows that in the north part, the low efficiency of old wells is mainly caused by high recovery degree, while infill wells are mainly caused by interlaminar interference. In the south part, the low efficiency of old wells is mainly caused by high recovery degree, while infill wells are mainly caused by thin and poor layer. Starting from the causes of low efficiency, the different adjustment directions are formulated for different causes.
North

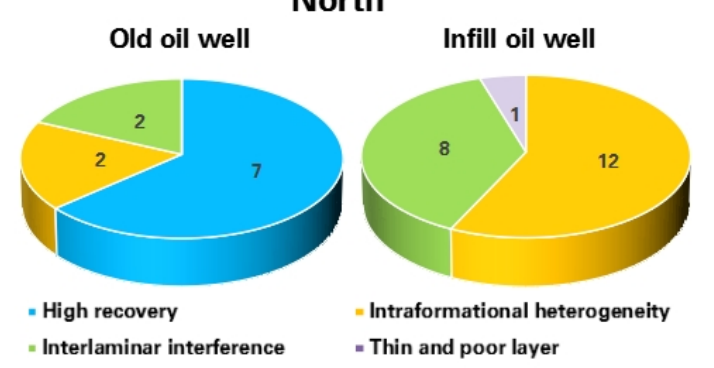

South

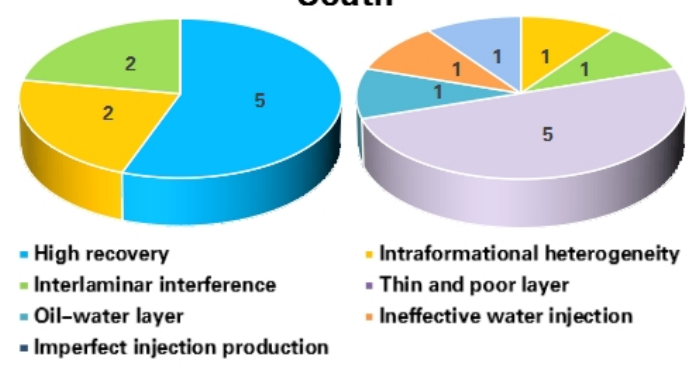

Fig. 3. Number of low efficiency wells of different types in S12 block. 


\section{Study on treatment measures for different types of low efficiency wells}

From the static characteristics of wells to the development history at home and abroad, the causes of low production and low efficiency wells are comprehensively analyzed. Comprehensive technical measures such as fracturing, converting oil well to water injection well, water plugging, well shut in and profile control are used to treat low production and low efficiency wells, and a set of treatment methods for low production and low efficiency wells are initially formed $^{[2-6]}$.

According to the actual geological and production situation of S12 block, in line with the principle of "partition in plane, classification in vertical, implementation potential, fine tapping potential, and maximum increase of single well production", carry out the comprehensive control measures such as improve the injection production system, reopen long shut in wells, and increase oil and water wells.

For the north part, interlaminar interference leads to poor production of non main layers, so it is the main idea to find out the remaining oil, implement the replacement layer and strengthen the poor layer production. For the south part, it is the main idea to implement the potential by well group and layer system, and local injection production adjustment combined with measures transformation.

Table 4. Number of wells with comprehensive treatment measures for low efficiency wells.

\begin{tabular}{|c|c|c|c|}
\hline \multicolumn{2}{|c|}{ Treatment methods and measures } & Number of wells / well & $\begin{array}{c}\text { Number of treatment wells / } \\
\text { well }\end{array}$ \\
\hline \multirow{3}{*}{$\begin{array}{c}\text { Improving injection } \\
\text { production relationship }\end{array}$} & Encryption adjustment & 7 & - \\
\cline { 2 - 4 } & Transfer notes & 3 & - \\
\cline { 2 - 4 } & to subdivide & 8 & 5 \\
\cline { 2 - 4 } & Hole mending & 5 & 4 \\
\hline \multirow{3}{*}{\begin{tabular}{c} 
Long shut in and reopen \\
\cline { 2 - 3 }
\end{tabular}} & Water injection adjustment & 4 & 8 \\
\cline { 2 - 4 } $\begin{array}{c}\text { Increase production and } \\
\text { injection of oil and water } \\
\text { wells }\end{array}$ & Tyclic water injection & 5 & 5 \\
\cline { 2 - 4 } & fracture & 5 & 6 \\
\cline { 2 - 4 } & Enlarge water injection & 6 & 3 \\
\hline
\end{tabular}

According to the formation reasons of different low efficiency wells, 48 wells were treated, 36 wells with low efficiency and long shut in are treated, accounting for $70.5 \%$ of the total (Table 4 ).

\section{Conclusions}

First, on the basis of fine geological description, using development data such as inspection well, dynamic test, water flooded layer interpretation and numerical simulation, comprehensively analyzing the production characteristics and remaining oil distribution characteristics of sand bodies of different origins, quantitatively predicting the remaining oil distribution and realizing the reservoir potential are the key to low efficiency well management.

Second, according to the distribution characteristics of the remaining oil potential of thick oil layers, exploring new measures to tap the remaining oil potential at the top of thick oil layers in the late stage of high water cut development and fully tapping the remaining oil at the top of main oil layers are the guarantee to improve the recovery degree of oil layers and control the decline.

Third, according to the distribution characteristics of remaining oil in the formation and the dynamic change law of single well, the internal causes of low efficiency wells should be clarified. Based on this, sub categories should be subdivided. Combined with the analysis of the effect of previous measures, it is the basis of making reasonable countermeasures.

\section{References}

1. Q. Clevis, P. de Boer, M. Wachter. (2003) Numerical modelling of drainage basin evolution and threedimensional alluvial fan stratigraphy. Sedimentary Geology, 163: 85- 110.

2. Li S.Q., Zheng J.. (2008) Research on the Genesis and Countermeasures of Low Production and Inefficient Wells in Oilfield Development. Inner Mongolia Petrochemical, 10: 237 238.

3. Liu M.X.. (2014) Cause and Management of Low Production and Low Efficiency Wells in the East of Pure Oil Area. Chemical Engineering \& Equipment, 1: 77 78.

4. Zeng Y.M.. (2014) Research on the Genesis and Countermeasures of Inefficient Wells in Middle Part of Saertu Oilfield. Journal of Yangtze University (Natural Science), 11: 67 68.

5. Meng J.X..(2015) Study on comprehensive treatment technology of low production and low efficiency wells in XX Development Zone. Inner Mongolia Petrochemical Industry, 12: 102 103.

6. Yang P.. (2013) Analysis on the causes of low efficiency well and its treatment scheme. Standards and quality of China Petroleum and chemical industry, 4: 173. 